\title{
A SYNOPSIS OF THE WOOD-DECAY GENUS LAXITEXTUM (HERICIACEAE, RUSSULALES, BASIDIOMYCOTA) AND A NEW SPECIES FROM CAMEROON
}

\author{
T. W. Henkel ${ }^{1} \&$ L. Ryvarden ${ }^{2}$ \\ Descriptions of and a key to the globally known species of the genus Laxitextum are provided. A \\ new species from Cameroon, Laxitextum globisporum, is described. \\ Keywords. Cameroon, new species, Russulales, tropical rain forest, wood-decay fungi. \\ Received 5 March 2020 Accepted 16 September 2020 Published 19 March 2021
}

\section{Introduction}

Laxitextum Lentz (Hericiaceae, Russulales, Basidiomycota) is a small genus of stereoid fungi originally erected by Lentz (1956 [1955]) to accommodate three species: L. bicolor (Pers.) Lentz, as the generic type, and L. crassum (Lév.) Lentz and $L$. roseocarneum (Schwein.) Lentz. The latter two species are currently excluded from Laxitextum and accepted as Phlebiopsis crassa (Lév.) Floudas \& Hibbett and Corticium roseocarneum (Schwein.) Hjortstam, respectively. Two more species of Laxitextum were subsequently described from tropical Africa (Hjortstam \& Ryvarden, 1981).

Laxitextum species can be differentiated from those of other stereoid genera with resupinate to bracket-like basidiomata by their smooth, pale-coloured hymenophores, enclosed gloeocystidia, and echinulate amyloid basidiospores. Our recent fieldwork from 2014 to 2019 has focused on ectomycorrhizal fungi associated with monodominant forests of the ectomycorrhizal canopy tree Gilbertiodendron dewevrei (De Wild.) J.Léonard in Cameroon. Wood-decay fungi have also been collected during this time. Here, we provide a global synopsis of known species of Laxtitextum and describe a new Cameroonian species as $L$. globisporum, based on its globose basidiospores.

\section{Genus description}

Laxitextum Lentz., U.S. Dept. Agric. Monogr. 24: 18 (1956 [1955]). - Type: Laxitextum bicolor (Pers.) Lentz.

Basidiomata resupinate or subpileate, rather soft and pliable, upper side brown, tomentose or when older with adpressed hairs, sometimes slightly zonate; hymenium white in fresh specimens; margin finely fibrillose in the resupinate state, smooth or somewhat tomentose

\footnotetext{
${ }^{1}$ Department of Biological Sciences, Humboldt State University, Arcata, CA 95521, USA. E-mail: twh5@ humboldt.edu.

${ }^{2}$ Institute of Biological Sciences, University of Oslo, PO Box 1066 Blindern, N-0316 Oslo, Norway.
} 
in pileate ones; hyphal system monomitic; hyphae thin-walled; cystidia smooth; basidia clavate, tetrasterigmate, with a basal clamp connection; basidiospores thin-walled, ellipsoid to globose, echinulate, amyloid.

Laxitextum, although a species-poor genus as currently known, is well characterised by its combination of stereoid basidiomata with brown trama and a white or pale-coloured subhymenial layer, enclosed or partly projecting gloeocystidia, and amyloid, echinulate basidiospores.

\section{Key to the known species of Laxitextum}

1a. Pileus dark brown and velutinate 1. L. bicolor

1b. Pileus absent, or if present, glabrous and cream to deep yellow 2

2a. Basidiospores 4-5 × 3-3.5 $\mu \mathrm{m}$, hyphae encrusted, gloeocystidia non-amyloid

3. L. incrustans

2b. Basidiospores smaller, hyphae smooth, gloeocystidia amyloid 3

3a. Spores elliptic, 3.5-4 × 3-3.5 $\mu \mathrm{m}$, pileus yellowish brown 4. L. lutescens

3b. Spores globose, $3-3.5 \mu \mathrm{m}$ in diameter, pileus ochraceous 2. L. globisporum

\section{Species descriptions}

1. Laxitextum bicolor (Pers.) Lentz., U.S. Dept. Agric. Monogr. 24: 19 (1956 [1955]). Figure 1. Thelephora bicolor Pers., Syn. Meth. Fung. 2: 568 (1801); Mycol. Eur. I: 122 (1822), nom. sanct. (Fr., Syst. Mycol. I: 438 [1821]).

Basidiomata resupinate or subpileate, upper side brown, in young specimens finely tomentose, in old specimens with more adpressed hairs, often indistinctly zonate and radially striate; hymenium in young fresh basidiomata pure white, darkening slightly to cream, then pale brownish, glabrous, cracking when dried, in section about $1 \mathrm{~mm}$ thick, the upper part of the trama (i.e. the subiculum of resupinate specimens), brown, the subhymenial part whitish; margin white and finely fibrillose in young specimens.

Hyphal system monomitic; hyphae of the brown trama distinct, with thin or somewhat thickened walls, light brown in the microscope, usually 2.5-4 $\mu \mathrm{m}$ wide; subhymenial hyphae thin-walled, in old basidiomata partly collapsed and forming a hyphal net with irregular meshes, penetrated by very thin-walled, cytoplasm-filled generative hyphae, these 1-3 $\mu \mathrm{m}$ wide.

Gloeocystidia present, in the young state fusiform, subulate, often with a moniliform apical appendix, more or less projecting, in old specimens tube-like, mostly obtuse, of highly varying length, 40-100 $\mu \mathrm{m}$ or longer, 5-10 $\mu \mathrm{m}$ wide, consistently filled with a yellowish oily substance. 


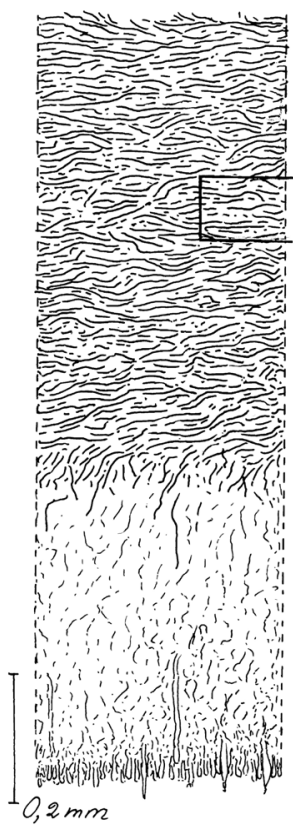

A

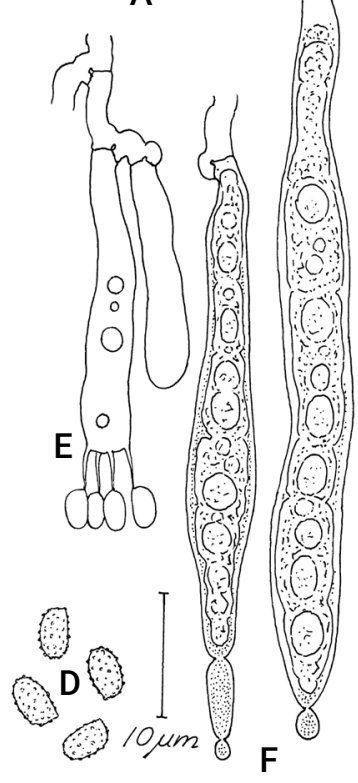

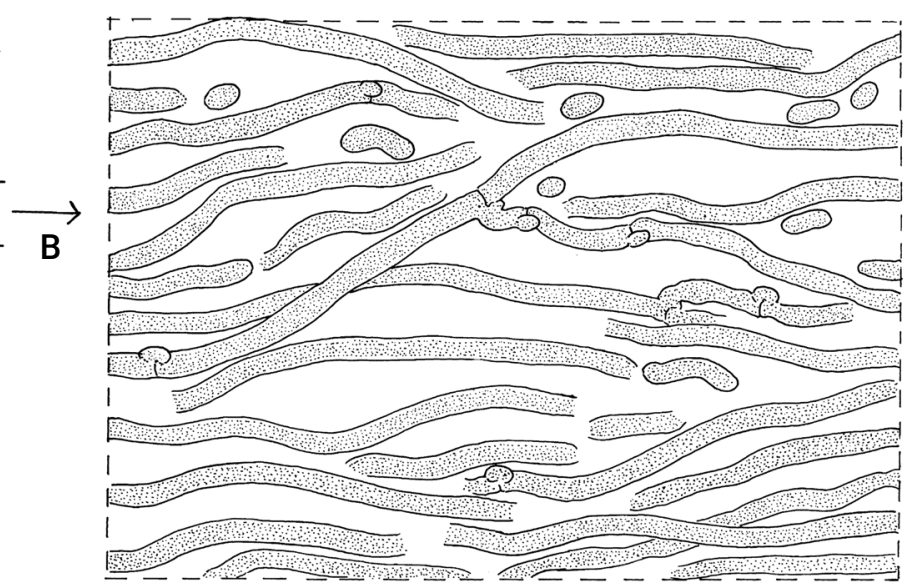

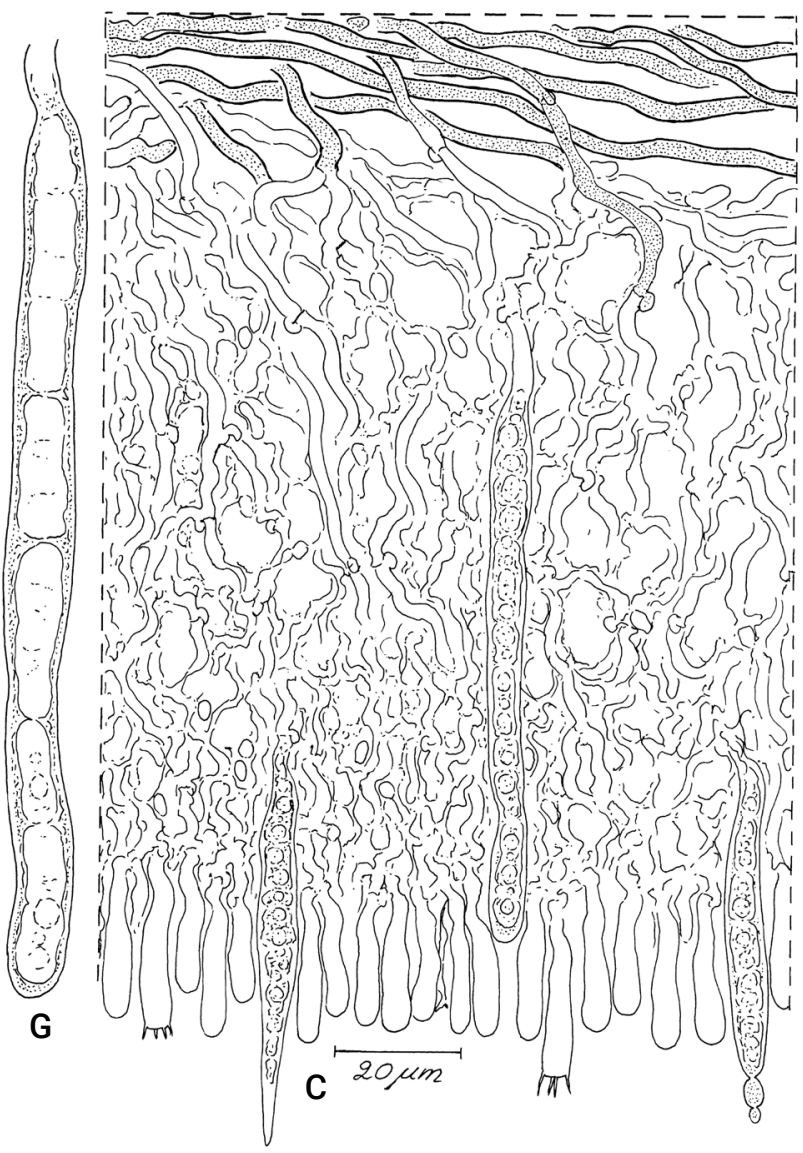

Figure 1. Microscopic features of Laxitextum bicolor. A, Section through the basidioma; B, tramal hyphae; $C$, subhymenium, cystidia, basidioles and basidia; $D$, basidiospores; $E$, mature basidium; F, young cystidia; G, older cystidium. Drawn from Eriksson 9318 (0) by J. Eriksson. 
Basidia narrowly clavate, $20-30 \times 3.5-5 \mu \mathrm{m}$, tetrasterigmate.

Basidiospores oblong-ellipsoid, thin-walled, finely echinulate, 4.5-5 × 2.5 $\mu$ m, amyloid.

Substratum. On decayed hardwoods.

Distribution. Cosmopolitan to $70^{\circ} \mathrm{N}$ in Norway.

Laxitextum bicolor is rather easy to recognise because of the contrasting brown upper and white lower colours and soft consistency.

2. Laxitextum globisporum T.W.Henkel \& Ryvarden, sp. nov.

Differs from all other Laxitextum species in its combination of ochraceous pileus and small, globose basidiospores. - Type: Cameroon, Region 3 East, Dja Biosphere Reserve, $3 \mathrm{~km}$ S of Somaloma village, 26 viii 2018, on stump of unknown hardwood tree, leg. $T$. Henkel 10753 (holotype YA; isotype HSC, 0). Index Fungorum 556984. Figures 2, 3.

Basidiomata flabelliform, semicircular, $20 \times 30 \mathrm{~mm}$, about $0.5 \mathrm{~mm}$ thick, flexible; pileus ochraceous, subzonate, smooth when fresh, when dry slightly radially wrinkled, bent, and curled; hymenial surface smooth, pale wood-coloured; hymenium in section dense, about $30 \mu \mathrm{m}$ deep; subhymenium distinct, pale ochraceous, 50-80 $\mu \mathrm{m}$ thick; trama rather loose and cottony, c.400 $\mu \mathrm{m}$ thick.

Hyphal system monomitic; hyphae with clamps; tramal hyphae loosely interwoven, pale yellow, 3-5 $\mu \mathrm{m}$ wide; oleiferous hyphae abundant in subhymenium and trama, yellow, distinctly amyloid, 4-6 $\mu \mathrm{m}$ wide.

Gloeocystidia present, 60-120 × 4-8 $\mu \mathrm{m}$, yellow, acuminate, distinctly amyloid.

Basidia 18-25 × 4-6 $\mu \mathrm{m}$, narrowly clavate, tetrasterigmate.

Basidiospores globose, 3-3.5 $\mu \mathrm{m}$ in diameter, a few subglobose, thin-walled, finely echinulate, amyloid.

Substratum. On decayed tropical hardwood stump.

Distribution. Known only from the type locality in the Dja Biosphere Reserve, Cameroon.

The ochraceous pileus and the small, globose basidiospores make Laxitextum globisporum a distinct species in the genus.

3. Laxitextum incrustans Hjortstam \& Ryvarden, Mycotaxon 13: 35 (1981). Figure 4.

Basidiomata resupinate, widely effused, often loosening from substratum along the margin; hymenial surface smooth, cream to ochraceous, more or less cracked in dry condition.

Hyphal system monomitic; hyphae with clamps, loosely interwoven, golden yellow, encrusted, 3-6 $\mu \mathrm{m}$ wide with thickened walls; oleiferous hyphae scattered to common, slightly amyloid. 


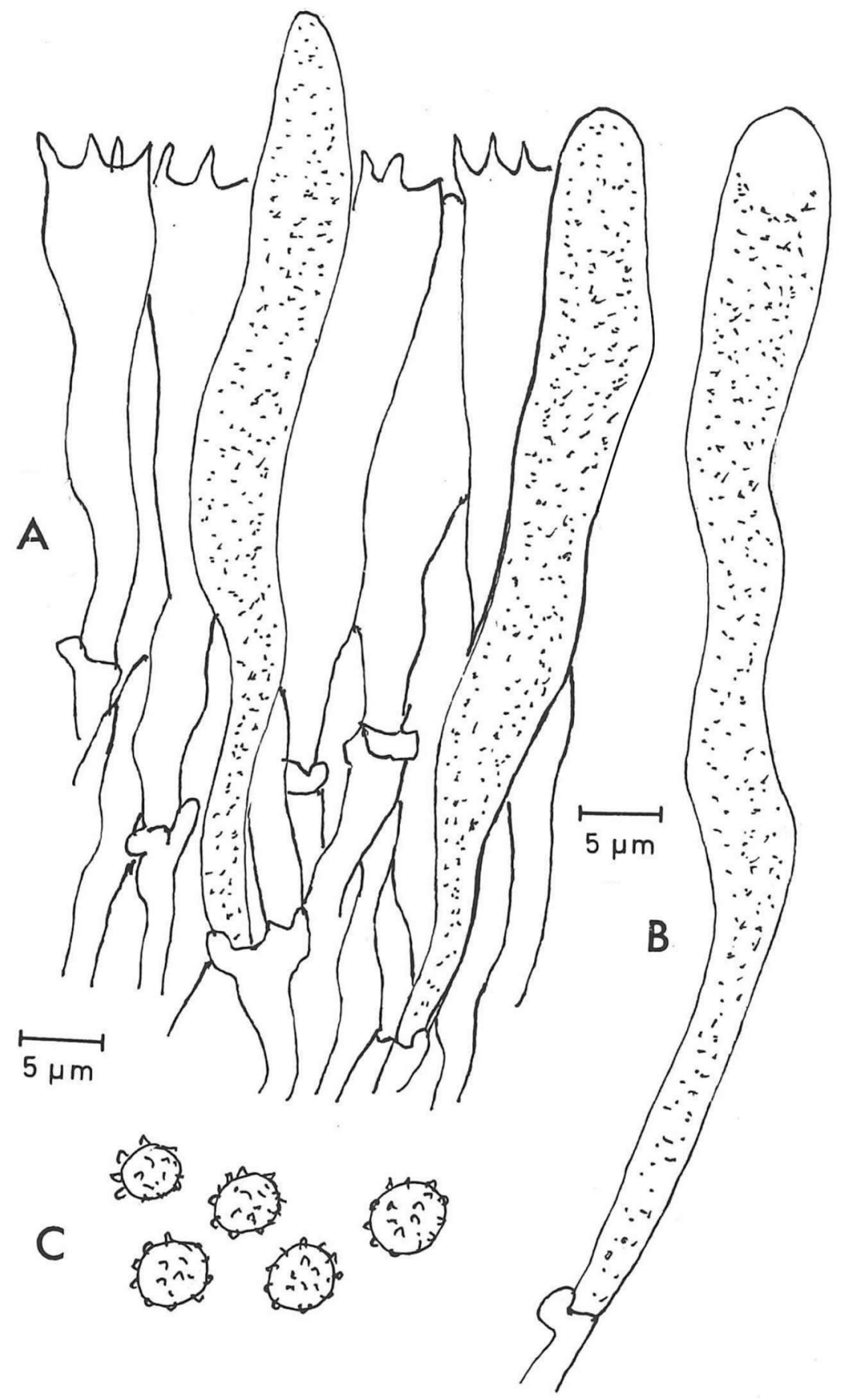

Figure 2. Microscopic features of Laxitextum globisporum T.W.Henkel \& Ryvarden, sp. nov. A, Basidia and gloeocystidia; B, mature gloeocystidium; C, basidiospores. Drawn from the holotype, Henkel 10753, by L. Ryvarden. 


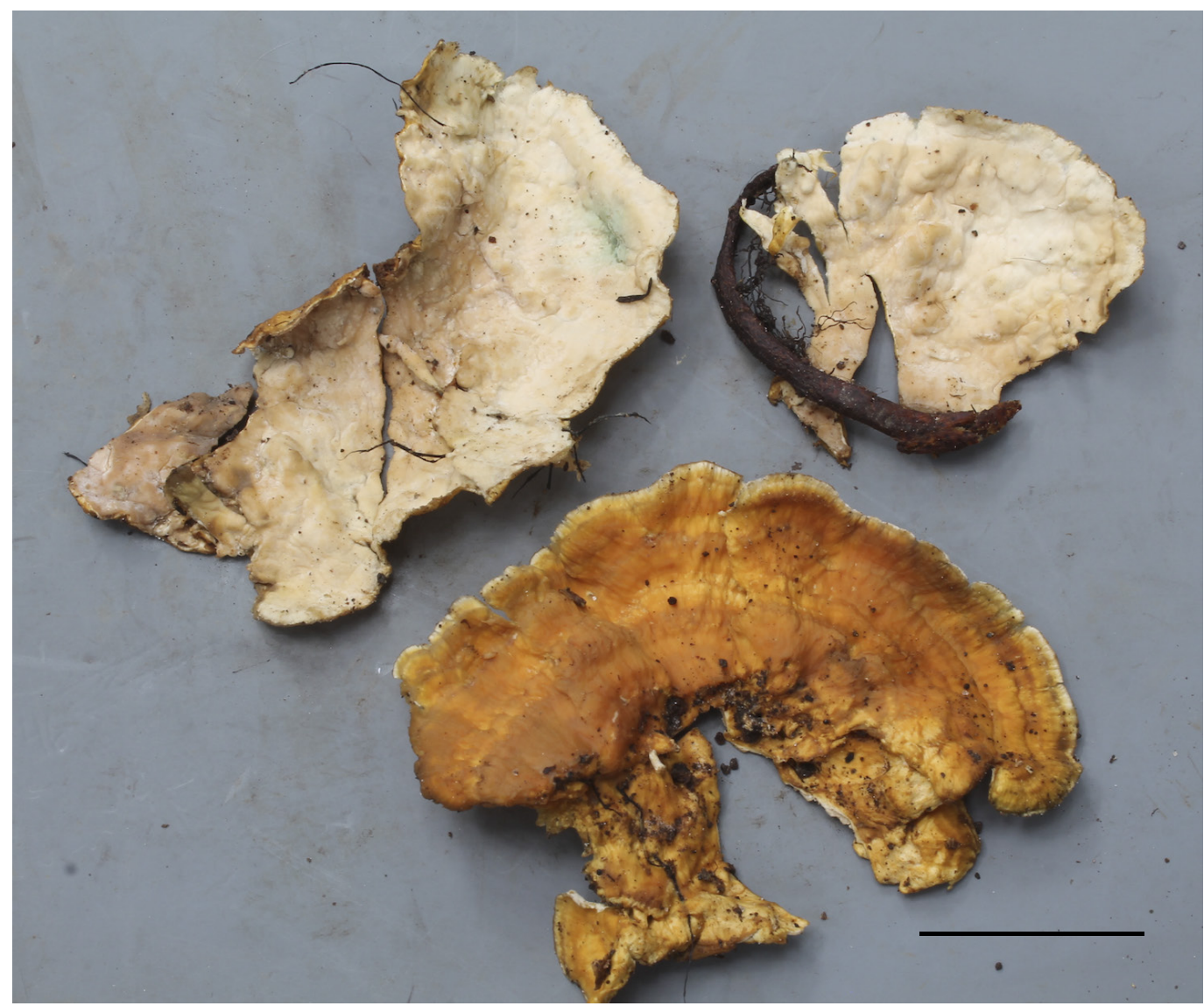

Figure 3. Laxitextum globisporum T.W.Henkel \& Ryvarden, sp. nov. Photograph of the holotype, Henkel 10753. Scale bar, $10 \mathrm{~mm}$. Photograph by T. W. Henkel.

Gloeocystidia present, in the young state fusiform, subulate, often with a moniliform apical appendix, more or less projecting, in old specimens cylindrical, mostly obtuse, $70-80 \times$ 4-6 $\mu \mathrm{m}$.

Basidia narrowly clavate, $15-25 \times 4-5 \mu \mathrm{m}$, tetrasterigmate.

Basidiospores 4-5 × 3-3.3 $\mu \mathrm{m}$, subglobose to ellipsoid, echinulate, strongly amyloid.

Substratum. On decayed hardwoods.

Distribution. Brazil, Cameroon, Ethiopia, Kenya, Tanzania, USA.

The resupinate basidioma shape and encrusted hyphae characterise this species.

4. Laxitextum lutescens Hjortstam \& Ryvarden, Mycotaxon 13: 40 (1981). Figure 5.

Basidiomata resupinate to pileate, $0.4-0.6 \mathrm{~mm}$ thick, pileus deep yellow to pale brown, 


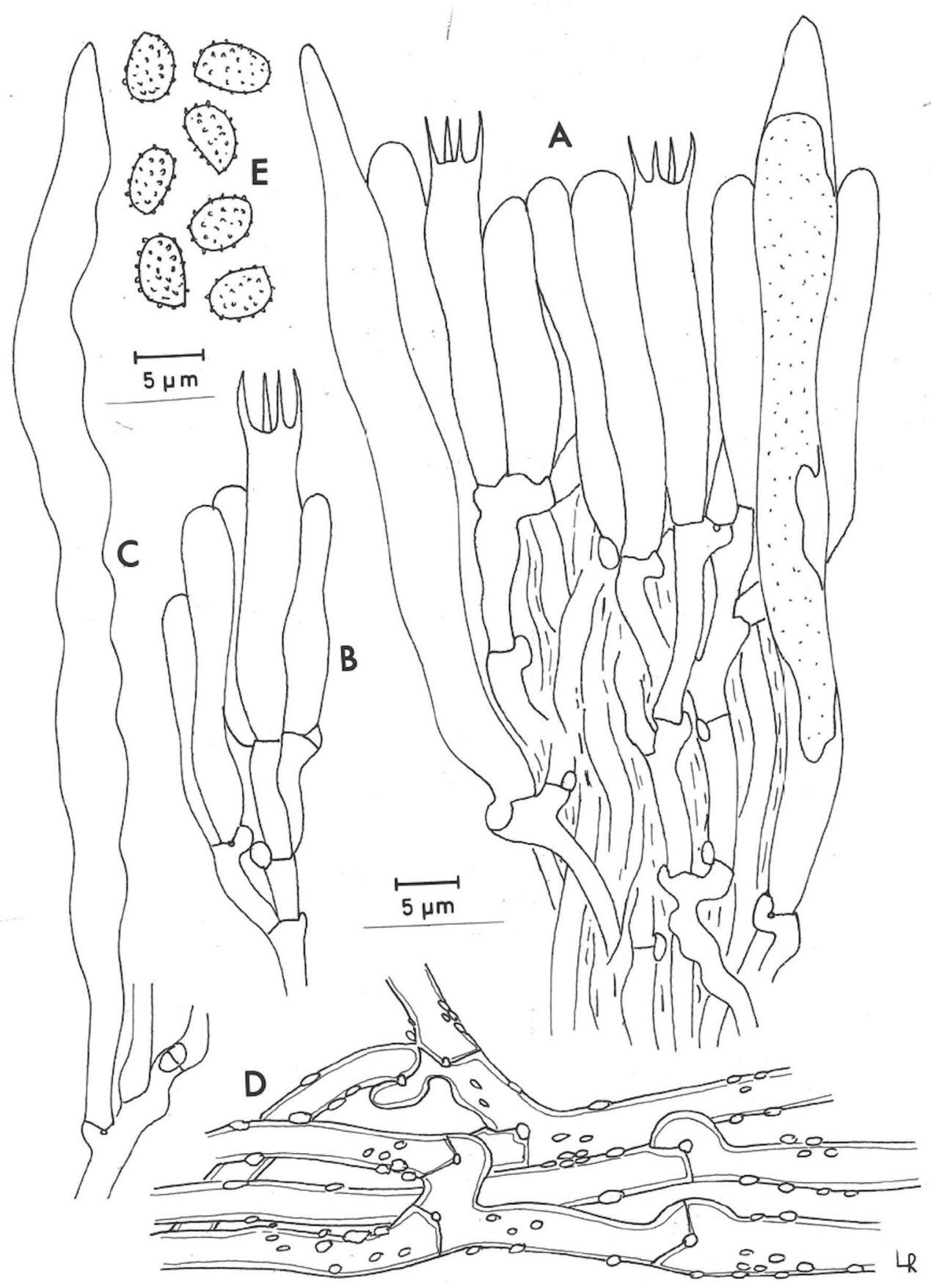

Figure 4. Microscopic features of Laxitextum incrustans. A, Section of the hymenium; B, basidioles and basidium; $C$, gloeocystidium; $D$, encrusted, clamped tramal hyphae; $E$, basidiospores. Drawn from the holotype, Ryvarden 10108 (O), by L. Ryvarden. 


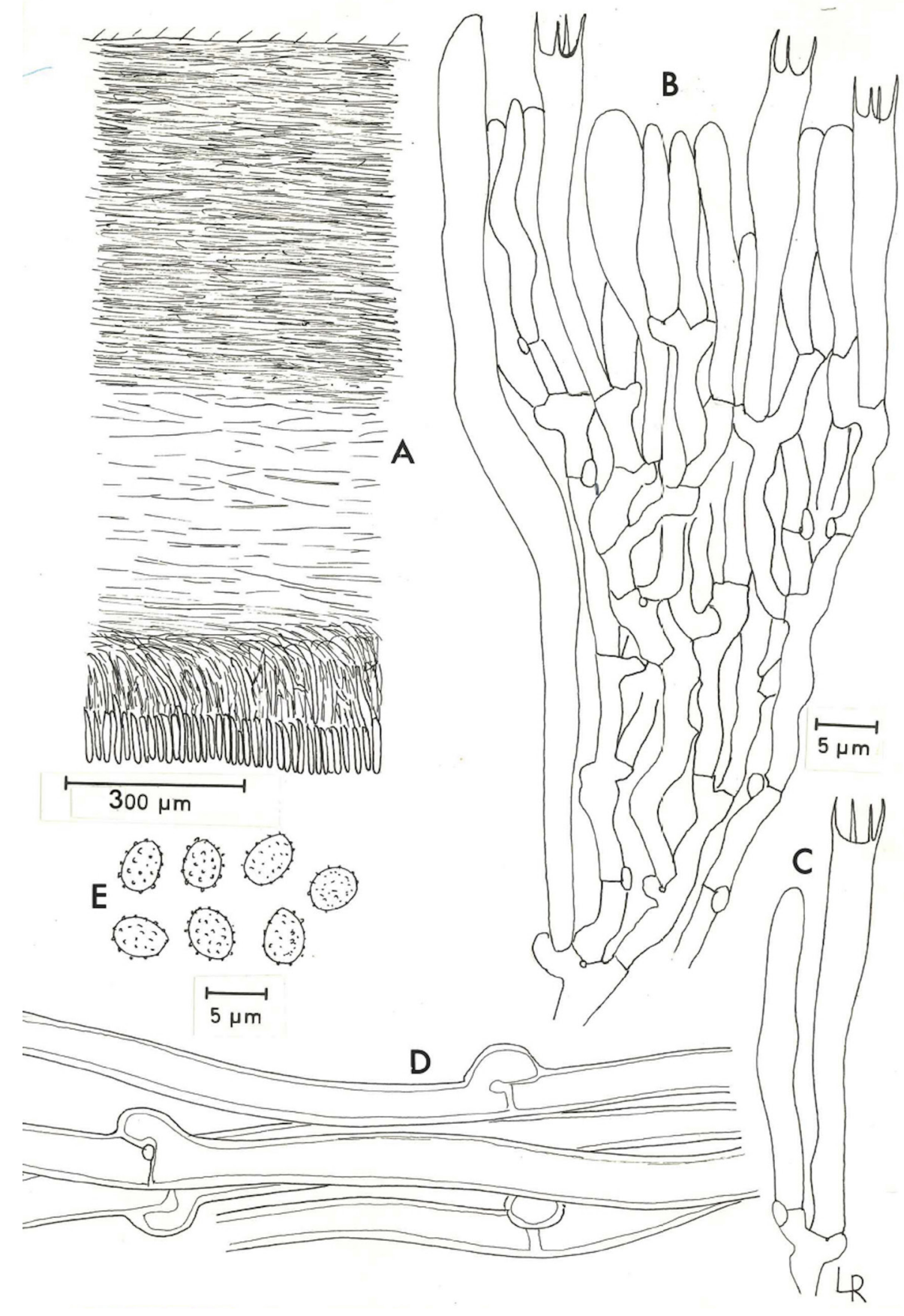

Figure 5. Microscopic features of Laxitextum lutescens. A, Section through the basidioma; B, section of the hymenium; $C$, basidiole and basidium; $D$, clamped subicular hyphae; $E$, basidiospores. Drawn from the holotype, Ryvarden 12875 (0), by L. Ryvarden. 
velutinate, azonate; hymenial surface cream-yellow to straw-coloured with a notably pale purplish brown tint; trama well developed, pale yellowish brown.

Hyphal system monomitic; hyphae with clamps; tramal hyphae loosely interwoven, pale yellow, 3-5 $\mu \mathrm{m}$ wide; oleiferous hyphae abundant in subhymenium and trama, distinctly amyloid, 4-6 $\mu \mathrm{m}$ wide.

Gloeocystidia present, $90-120(-200) \times 6-9 \mu \mathrm{m}$, in the young state fusiform, subulate, often with a moniliform apical appendix, occasionally up to $200 \mu \mathrm{m}$ long, distinctly amyloid.

Basidia narrowly clavate, $20-25 \times 4-5 \mu \mathrm{m}$, tetrasterigmate.

Basidiospores $4 \times 3-3.3 \mu \mathrm{m}$, subglobose to broadly ellipsoid, thin-walled, finely echinulate, amyloid.

Substratum. On decayed hardwood.

Distribution. Cameroon, Ghana.

The species is similar to Laxitextum bicolor but differs in its deep yellow upper surface, amyloid gloeocystidia, and smaller basidiospores.

\section{Acknowledgements}

Funding was provided to T. W. Henkel by the National Science Foundation grant DEB-1556338. Valuable financial support was provided to L. Ryvarden from the Nansen Foundation/Norwegian Academy of Sciences. In Cameroon the Ministry of Research and Scientific Innovation issued research permits. The Conservator of the Dja Biosphere Reserve, Mr Ndinga Hilaire, and his staff, greatly assisted with the fieldwork in the Dja. Congo Basin Institute staff provided much logistical support. Field assistance in Cameroon was provided by Mei Lin Chin, Kennan Mighell, Olivier Séné, Alamane Gabriel (aka Sikiro), and Essambe Jean-Pierre (aka Papa Chef).

\section{References}

Hjortstam K, Ryvarden L. 1981. Studies in tropical Corticiaceae III. Two new species of Laxitextum. Mycotaxon. 13(1):35-40.

Lentz PL. 1956 (1955). Stereum and allied genera of fungi in the upper Mississippi valley. Agricultural Monographs, United States Department of Agriculture. 24:1-74. https://doi.org/10.5962/bhl. title.63676 